\title{
GIGA-MAPPING AND KNOWLEDGE OF BOUNDARY OBJECT THEORY IN SUSTAINABLE PRODUCT DEVELOPMENT
}

\author{
Eva KVAM \\ OsloMet - Oslo Metropolitan University
}

\begin{abstract}
New combinations of disciplines allow a better understanding of interconnected modern problems like sustainability. Expanding design education curriculum may improve a designer's ability to deal with complex subject matters where expertise and perspectives from other fields are needed.

Through the theoretic lens of 'Boundary objects', one can describe how GIGA-mapping employs certain collaborative characteristics and can provide a better overview of decisions in complex subject matters. GIGA-mapping is a method in system-oriented design, a growing area of interest in the field of design. The process of GIGA-mapping can also be used in product development, especially for understanding the context of a new product, its environmental impact, production processes or alternative value chains. What makes a GIGA-map serve as a boundary object, and why are GIGA-mapping and boundary object theory useful in product development processes? The paper builds on perspectives and learnings from a master's student, discussing topics that could be valuable in design education. The theory of boundary objects provides interesting perspectives on the characteristics of objects or tools that enable communication across knowledge boundaries. Such perspectives are useful in design education because of the increasing need for collaborative work and the high number of considerations involved when developing more sustainable solutions. Incorporating awareness of boundary objects in design education may improve processes that require collaboration across disciplinary boundaries.
\end{abstract}

Keywords: Boundary object, GIGA-map, product development, complexity, collaboration

\section{INTRODUCTION}

In this fast-paced globalised world, big environmental issues and social challenges create opportunities for using design methods in complex modern challenges. So called $21^{\text {st }}$ century problems are hard to solve for many reasons, due partly to their interconnectedness with other problems. Such problems have been described as 'mess' [1] or 'wicked problems' [2,3]. When levels of complexity and uncertainty rise, finding the actual root cause is difficult. Curtis et al. [4] quote a statement from a system engineer: 'Writing code isn't the problem; understanding the problem is the problem' [4]. Product developers face complex considerations such as sustainability choices, production technologies and diverging interests in a product's value chain. Product development projects are, therefore, often dependent on collaboration across knowledge fields. In a real-world project setting, organisational silo structures and differences in language or practice might also cause communication difficulties, and common ground is needed for good collaboration and progress [6]. Building on Bourdieu's forms of knowledge, Carlile [7] highlights how a pragmatic approach to knowledge recognizes that knowledge is 'localized, embedded, and invested in practice', explaining why it is both a barrier to and a source of innovation in a product development setting. In light of the increasingly interdisciplinary problems designers and product developers face, new methods of combining knowledge should emerge. GIGA-mapping [5] is a promising approach that utilises visual communication to portray and handle complexity.

\section{BACKGROUNDS}

With systems theory [8] and systems thinking, one can better describe and understand the behaviour and patterns of the complexity around us. Natural living phenomena, or even businesses and interactive products, can be seen as interconnected 'wholes' integrated with their environment. Paying attention to this, the designer can better analyse the context of an existing or potential new solution to reach a better 
implementation fit. System-oriented design (SOD) [5] is based on systems thinking and systems practice, design thinking and design practice, and visual thinking and visual practice. SOD is tailored for designers, and central to SOD is the GIGA-mapping technique [5].

\subsection{GIGA-mapping}

A GIGA-map can contain multiple layers and levels of detail and can also incorporate several types of maps in one. It can serve as a 'desktop' of thoughts and ideas put into context. A GIGA-map focuses on relations and links between various elements put on the map. It is a way of seeing everything at once, while still being able to zoom into and investigate or elaborate details. The constant and ongoing process of sense-making [9] is central to GIGA-mapping. We 'structure the unknown' [10] and try to make sense of something that is at first hard to grasp, interpret or understand, in order to construct meaning. One way to do this is to take a preferably large piece of paper, jot down ideas, words and sketches, map out relations between contexts and situations, and try to understand and improve behaviour or phenomena. We then see a bigger picture and can compare and envision possibilities for action. Sensemaking is about an activity or a process, it is about creation as well as discovery [11]. GIGA-mapping can thus be considered as the activity of investigating and understanding the complex context of the 'upcoming change to be'. Changes are seldom applied in isolation because a new product or technological solution will impact something else: the environment, human behaviour or industrial efficiency. Although GIGA-mapping as an activity can be done completely alone, it is intended as a collaborative tool that can collect and negotiate the perspectives and input from the group or stakeholders and from interviews or research conducted by others.

\begin{tabular}{|c|c|c|c|c|c|c|c|c|}
\hline & Reseounch & Leaming & Genentive & Mnageneent & Event mapping & Preming & Inmovaton & Inplenentition \\
\hline Undmapa & $x$ & $x$ & & & & & & \\
\hline Concegt nupe & $x$ & $x$ & & & & $\mathrm{x}$ & $x$ & \\
\hline Gentt dagans & & & & $x$ & $x$ & $x$ & & $x$ \\
\hline Tinelines & & $x$ & & $x$ & $x$ & $x$ & $x$ & $x$ \\
\hline Key tanes & & $x$ & $x$ & & $x$ & & & $x$ \\
\hline Fleschats & & & & & & $x$ & & $x$ \\
\hline Arimatores & & & $x$ & & $x$ & & & $x$ \\
\hline Storyboents & & & $x$ & $x$ & $x$ & & $x$ & $x$ \\
\hline Inage maps & $x$ & $x$ & $x$ & & & & $x$ & \\
\hline Spporar mage & $x$ & & $x$ & & $x$ & $x$ & & $x$ \\
\hline hloredy mape & $x$ & & $x$ & & $x$ & & $x$ & \\
\hline Wrood mapes & $x$ & $x$ & $x$ & $x$ & $x$ & $\mathrm{x}$ & $x$ & $x$ \\
\hline
\end{tabular}

Figure 1. A table by Sevaldson [5] shows a non-exhaustive list of suggestions for matching map types and activities.

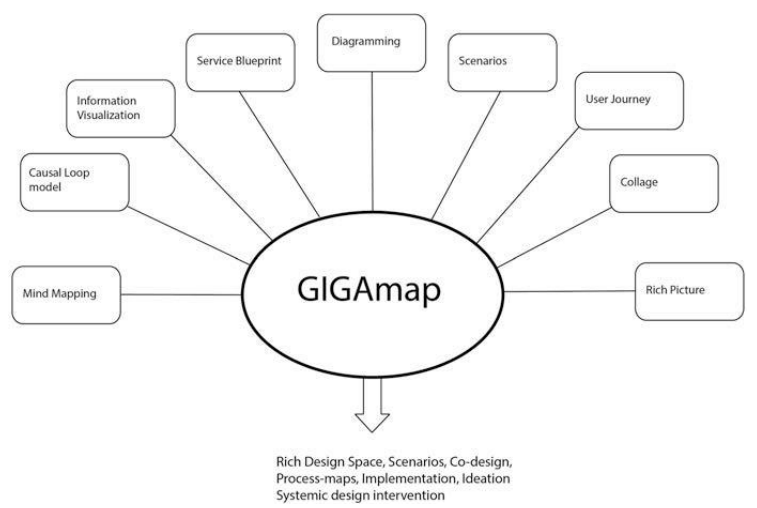

Figure 2. The GIGA-map earns its name not only from the number of elements that it should contain but also from the numerous representative modes and models it might integrate. Retrieved from [12] 


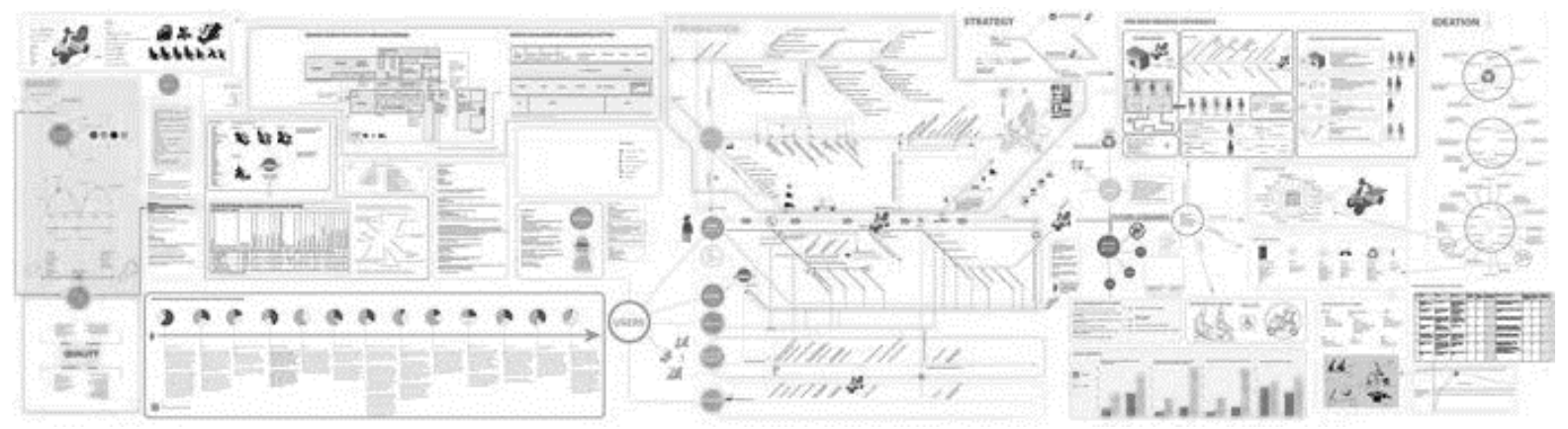

Figure 3. A GIGA-map of a Norwegian manufacturing company (Medema). The GIGA-map can express models of relations and interconnectedness to timelines, floor plans, statistics, and illustrations. by Julian Guribye and Christian von Hanno, AHO 2011, retrieved from [12]

Knowledge transfer and utilisation increase in complexity when actors from different backgrounds, sectors and disciplines come together to solve these kinds of problems in what [13] calls a 'boundaryspanning group'. Even departments within the same organisation can have 'knowledge boundaries' that cause communication difficulties, like in interactions between designers and engineers or other specialised functions [7]. According to [7], using a 'boundary object' can be a means of 'representing, learning about, and transforming knowledge' across boundaries of knowledge that separates organization departments or disciplines. Star \& Griesemer [14] were the creators of the term 'boundary object'. They extended the Latour-Callon model of interessement to highlight two main activities central to translate between viewpoints. They saw that the standardisation of methods and the development of 'boundary objects' enabled groups of divergent visions and practices to collaborate without letting go of their own agenda. Despite the different definitions, boundary objects have some common aspects: (a) may be an abstract or concrete object, (b) must be 'plastic enough to adapt to local needs', (c) must be 'robust enough to maintain a common identity across sites' [14], (d) must be temporal, (e) must be based in action, meaning its materiality must derive from actor's action; and (f) must be subject to reflection or interpretive flexibility [15]. GIGA-maps have been described as bridging artefacts [12], but from what I could find, not through the term boundary object. GIGA-mapping encourages cross-disciplinary collaboration that 'entertains' input from different perspectives. This can be done through methods such as interviews, where data is collected and put into the map by the designer or by workshop participants and can later be a part of or feed into the 'main map' worked on by the designers or facilitator group. Based on the collaborative nature of the GIGA-mapping process and its tendency to cause negotiation and discussion, I will look further into the boundary-spanning and boundary-object properties in GIGA-maps. Therefore, this paper will bring additional perspectives to the lively discussion on boundary objects through comparison with GIGA-mapping processes and characteristics of GIGA-maps. It will also discuss the value of increasing awareness of these concepts through design education.

\section{RESEARCH QUESTION}

This paper will discuss GIGA-mapping through the concept of boundary objects. I have not found any other paper comparing these concepts. The research question is: What makes a GIGA-map serve as a boundary object, and why are GIGA-mapping and boundary object theory useful in product development processes?

\section{METHODS}

This paper will draw on existing research on GIGA-mapping and boundary objects, together with relevant topics found through a literature search. Contributions to the discussion also stem from being in the field of design/engineering and from being student using GIGA-mapping in design projects.

\section{BOUNDARY OBJECTS AND GIGA-MAPS}

Since design and product development are much about the creation of change, the process of GIGAmapping requires inquiry and negotiation and involves frequent decision-making on the next pathways. The processes of sensemaking and framing contribute to refining the contours of both the problem space and the solution space $[13,16]$. GIGA-mapping can create great synergies caused by the ability to 
understand the status quo better and envision the changes of how things 'ought to be'. The GIGA-map format is deliberately left open [12] to avoid losing sight of potentially crucial details and make its format flexible enough to be used in different worlds. Having close collaboration with relevant actors and stakeholders reduces the risk of not being on the same page later when the costs of turning back are higher. The dynamics of the design process can be described as layers and iterations of interactions initiated by the designer. These processes may take various forms, with different degrees of stakeholder involvement, external participation or co-design. The way the GIGA-mapping process is carried out is a crucial factor in discussing how the 'unfinished' Giga-map may successfully employ boundary object characteristics.

\subsection{Boundary object characteristics}

The concept of boundary objects arose from observing how different actors with different self-interests at the Museum of Vertebrate Zoology worked together. A boundary object facilitates communication between social worlds and is plastic enough to be used in all of them. Often the 'local' use or elaboration of the boundary object might be more detailed or adapted to specific local needs. When used in group settings, one can discuss and share perspectives because the object is still recognisable to others. The object can be further developed by the team members separately or together. Nicolini et al. [17] described these behaviours from their experiments and mentioned how the 'unfinished nature' of a prototype caused a kind of motivation for the group to work towards finalisation, similar to what Knorr Cetina described in epistemic objects [18]. Through this drive to move forward, the attachment to the object increased as they could embed their own ideas and visions into it.

From my perspective, collaborative mapping processes can be seen as a boundary-spanning activity, where the designer or facilitator aims to gather, interweave and consolidate different and multiple perspectives and areas of knowledge. When actors can actively put their own ideas into the 'unfinished' GIGA-map, it could lead to an improved sense of involvement or motivation similar to what is described in the examples of [17] and [18] above. The rest of the group may thereafter update themselves and discuss the meaning of the perspectives added.

Lee [19] observed how designers were using artefacts and surrounding practices to coordinate perspectives and to align diverse groups of people. Often this process was temporary and, in iterations, a means of solving specific design problems in a large design project. In the design field, this can be sketches, 2D or 3D models, probes, prototypes, mock-ups, mood boards, different kinds of maps and more. Even Gantt charts may cause discussion and negotiation [20]. Studies of boundary objects and those using them have identified diverse types of boundary objects and highlighted some of the properties [21], such as modularity, abstraction, accommodation and standardisation. According to Levina and Vaast [21], researchers have also investigated what makes these objects effective. Such objects are described as tangible, concrete, accessible and up to date [21]. Listing these properties may be useful for recognising future potential boundary objects. According to Wenger [22], the design of artefacts such as documents, systems or tools is actually often about the design of boundary objects.

\subsection{Earning the status as a boundary object}

Susan Star [15] tried in 2010 to add clarity to the confusion that had built up around boundary objects after the introduction of the concept in 1989 [14]. Susan Star emphasised that one of the least discussed aspects of their original study [14] was that boundary objects 'are a sort of arrangement that allows different groups to work together without consensus' [15]. The same is said about the GIGA-mapping process [12]. In both situations, people seem to be able to work side by side with both overlapping interests and diverging ones.

An object's status as a boundary object may change and vary over time [19]. This means that even though a 'work in progress' GIGA-map might be a promising boundary object; it does not automatically claim this status if it does not provide the collaborative or boundary-spanning effects. Levina and Vaast [21] highlight that objects alone may not have a successful boundary object effect. It is the adoption, incorporation and 'ongoing use' of these artefacts that embed them in the situated practices of those using them. A teacher in design, commented a slight scepticism towards the notion that boundary objects themselves facilitate discussion if only 'put on a table with people around'. There is often a need for some kind of facilitation or communication linked to the objects. 


\subsection{Critical perspectives and limitations}

As the artefacts are defined by the way they are used and not solely by their intrinsic 'metrics', Lee [19] argues that the term 'boundary object' seems too broad, explaining that other artefacts also 'live' in the space between different areas of practice. This point of view is also reported elsewhere [17, 24]. How the taxonomy of these kinds of objects should be is an ongoing discussion that needs further synthesis work [24]. Anyhow, it is the characteristics of the effects and dynamics around these boundary objects which in my opinion are of interest, and which have been the main topic in this paper. It is also important to mention that the different names and meanings of such objects can confuse transdisciplinary research. Even though the term boundary object might seem imprecise and over-used to some, the insights of the phenomena it describes are, in my opinion, still valuable. The concept of boundary objects in collaboration relates closely to the way designers use $2 \mathrm{D}$ and 3D artefacts in interactive and iterative dialogue or conversation [23] with recipients, particularly in the design process. Once the artefact or boundary object is 'finished', there is no longer any gap of 'unfinishedness' to fill and continuing the dialogue for further ideas makes less sense. At this stage, it seems like the object changes status when there is no longer a need for collaborative input. It is then, at best, a piece of work to be admired and valued in other ways.

The effects described by Star and Griesemer, which led to the concept of boundary objects, show many similarities with effects observed in GIGA-mapping processes. These qualities could be investigated further. The divergent terminology in the description of such objects or phenomena is still up for debate, and not all varieties have been included in this paper. More work is needed to achieve a full overview.

\section{CONCLUSIONS}

A designer's work revolves around problem-solving and change-envisioning. Designers use maps, objects and prototypes as means of translating ideas, forms and visions into tangible or abstract and discussable platforms for change. Systemic design methods such as GIGA-mapping may be useful for different product development processes. GIGA-mapping could in fact be used when mapping out everything from business models, production floor activities, life cycle assessments, and more. GIGAmaps can be especially helpful when contextualising the environment of a new product before implementation, and when involving different knowledge perspectives in a project. The new product is, in fact, entering a system of relations, monetary flows, webs of organisations, and the natural and sociotechnical ecosystem. Product developers should therefore to a greater extent evaluate the effects of new products brought to the markets, the environment and the society, and know the following consequences. Having an overview of the field in which you are navigating can improve decision-making on complex subject matters, and GIGA-mapping is one way of obtaining that overview. When serving as an input for decision-making, the knowledge revealed through the GIGA-mapping process is crucial, especially when major decisions are taken based on the information in it. A comprehensive mapping process with external expert input can serve as a better basis for strategic decision-making and for envisioning of future scenarios.

Cross-boundary collaboration often faces challenges of silo structures, different terminologies, cultures and practices that cause misunderstandings or barriers that can be hard to overcome. Building on the theory of boundary objects, increased awareness of collaboration dynamics in design education can enable better collaboration across diverse fields. When one knows the characteristics of boundary objects, one might more easily employ these in various tools and templates to facilitate discussion and successful knowledge exchange in collaborative projects or product development work.

\section{REFERENCES}

[1] Ackoff R. L. The Art and Science of Mess Management. Interfaces, 1981. 11(1): pp. 20-26.

[2] Buchanan R. Wicked Problems in Design Thinking. Design Issues, 1992. 8(2): pp. 5-221.

[3] Rittel H. W. J. and Webber M. M. Dilemmas in a general theory of planning. Policy Sciences, 1973. 4(2): pp. 155-2169.

[4] Curtis B., Krasner H. and Iscoe N. A field study of the software design process for large systems. Communications of the ACM, 1988. 31(11): pp. 1268-1287.

[5] Sevaldson B. GIGA-mapping: Visualisation for complexity and systems thinking in design. Nordes, 2011(4).

[6] Bechky B. A. Sharing meaning across occupational communities: The transformation of understanding on a production floor. Organization Science, 2003. 14(3): pp. 312-2330. 
[7] Carlile P. R. A pragmatic view of knowledge and boundaries: Boundary objects in new product development. Organization Science, 2002. 13(4): pp. 442-2455.

[8] Bertalanffy L.V. General System Theory: Foundations, Development, Applications. Revised edition. D. Rousseau and W. Hofkirchner (eds.) 2015, New York: George Braziller Inc. XXXVI, 295 pages.

[9] Weick K. E., Sutcliffe K. M. and Obstfeld D. Organizing and the process of sensemaking. Organization Science, 2005. 16(4): pp. 409-2421.

[10] Waterman R. Adhocracy: The Power to Change (Larger Agenda Series). Knoxville, TE: Whittle Direct Books, 1990.

[11] Weick K. E. Sensemaking in Organizations. Vol. 3. 1995: Sage.

[12] Sevaldson B. Visualizing complex design: The evolution of gigamaps. Systemic Design. 2018, Springer. pp. 243-2269.

[13] Gasson S. The Dynamics of Sensemaking, Knowledge, and Expertise in Collaborative, Boundary-Spanning Design. Journal of Computer-Mediated Communication, 2017. 10(4).

[14] Star S. L. and Griesemer J. R. Institutional Ecology, 'Translations' and Boundary Objects: Amateurs and Professionals in Berkeley's Museum of Vertebrate Zoology, 190739. Social Studies of Science, 1989. 19(3): pp. 387-2420.

[15] Star S. L. This is Not a Boundary Object: Reflections on the Origin of a Concept. Science, Technology, \& Human Values, 2010. 35(5): pp. 601-2617.

[16] Dorst K. and Cross N. Creativity in the design process: Co-evolution of problem-solution. Design Studies, 2001. 22(5): pp. 425-2437.

[17] Nicolini D., Mengis J. and Swan J. Understanding the Role of Objects in Cross-Disciplinary Collaboration. Organization Science, 2012. 23(3): pp. 612-2629.

[18] Cetina K. K. Epistemic Cultures: How the Sciences make Knowledge. 2009: Harvard University Press.

[19] Lee C. P. Boundary Negotiating Artifacts: Unbinding the Routine of Boundary Objects and Embracing Chaos in Collaborative Work. Computer Supported Cooperative Work (CSCW), 2007. 16(3): pp. 307-339.

[20] Yakura E. K. Charting time: Timelines as temporal boundary objects. Academy of Management Journal, 2002. 45(5): pp. 956-970.

[21] Levina N. and Vaast E. The Emergence of Boundary Spanning Competence in Practice: Implications for Implementation and Use of Information Systems. MIS Quarterly, 2005. 29(2): pp. 335-363.

[22] Wenger E. Communities of Practice: Learning, Meaning, and Identity. 1999: Cambridge University Press.

[23] Dubberly H. and Pangaro P. Cybernetics and design: Conversations for action. Design Cybernetics. 2019, Springer. pp. 85-299.

[24] Koskela L. et al. Towards shared understanding on common ground, boundary objects and other related concepts. Proc. 24th Ann. Conf. of the Int'l. Group for Lean Construction, Boston, MA, USA, 20-22 July 2016. 2016. 